\title{
Kimberlitic fluid as recorded by dissolving diamonds and crystallizing olivine phenocrysts in five Lac de Gras kimberlites, Northwest Territories, Canada
}

\author{
Yana Fedortchouk ${ }^{1}$, Sergei Matveev ${ }^{2}$, Courtney Charnell ${ }^{3}$ and Jon A. Carlson ${ }^{3}$ \\ ${ }^{1}$ Dept. Earth Sciences, Dalhousie University, Halifax, Canada \\ ${ }^{2}$ Dept. Earth and Atmospheric Sciences, University of Alberta, Edmonton, Canada \\ ${ }^{3}$ BHPBilliton Diamonds Inc., Kelowna, Canada
}

\section{Introduction}

The volatile composition of kimberlites is not well known. Original proportions of the two main volatiles, $\mathrm{H}_{2} \mathrm{O}$ and $\mathrm{CO}_{2}$, are obscured by complex origin of some groundmass carbonates and hydrous minerals. Volatiles play a vital role in diamond preservation. As $\mathrm{H}_{2} \mathrm{O}$ - and $\mathrm{CO}_{2}$-rich magmas have different depth of volatile exsolution and character of eruption (Papale and Polacci, 1999), composition of volatiles may affect the geology of kimberlite pipes (Skinner and Marsh, 2004). Experimentally demonstrated distinctive difference in the character of diamond resorption in magmas with $\mathrm{H}_{2} \mathrm{O}$ - or $\mathrm{CO}_{2}$-rich fluids allows using diamond surface for investigating kimberlitic fluid (Fedortchouk et al. 2007). In addition, water fugacity of kimberlitic magma can be estimated using water content in phenocrystal olivine measured by FTIR spectroscopy (Matveev and Stachel, 2007). We apply these two independent methods to several kimberlites with various geology, compositions and diamond populations in order to: 1) refine methodology for investigating a kimberlitic fluid, 2) to constrain the composition and the behavior of volatiles, presence of a free fluid phase in these kimberlites and 3) to evaluate the effect of the fluid on diamond population and the geology of a kimberlite.

\section{EKATI kimberlites and their diamonds}

The study uses micro- and macro-diamond populations from four EKATI mine property kimberlites: Leslie, Grizzly, Koala and Misery, and olivine concentrates and kimberlite core from six pipes including Panda and Beartooth kimberlites. These kimberlites have similar emplacement ages, erosion level, and wall-rocks, and nevertheless some filled with magmatic (MK) and others with volcaniclastic kimberlite (VK). The diamond populations also show a large variation in the degree and character of resorption and the diamond grade (Gurney et al., 2004, Fedortchouk et al., 2005). Grizzly and Leslie are the only kimberlites filled with MK. They have low diamond grade (around 0.5 carats/ tonne), generally poor diamond quality, and high proportion of ronded (resorbed) stones. Beartooth and Panda kimberlites are VK-filled pipes with medium diamond grade (around $1 \mathrm{cts} / \mathrm{t}$ ) and predominantly octahedron diamond forms. Koala (1 cts/t) and Misery (4 cts/t) both have very high proportion of rounded hexoctahedron diamonds and very few primary octahedron forms. Both kimberlites are filled with VK. However, Misery is a complex multi-phase pipe with some hypabyssal dykes of MK.

\section{Dissolution features on diamonds}

Diamond dissolution experiments (Fedortchouk et al., 2007) demonstrated that the resorption features common for natural diamonds can be produced only in the presence of a free fluid phase, where an absence of fluid would develop surface graphitization on diamonds. $\mathrm{H}_{2} \mathrm{O}$-rich and $\mathrm{CO}_{2}$-rich fluids produce distinctively different dissolution features on diamonds. In some of these experiments the fluid was lost due to the capsule unsealing and the diamonds developed very different resorption features with sharp-spiked micro step-faced surfaces (Fig.1e,g) (see Fedortchouk et al., 2007, for the experimental methods). In this study we are applying the results of these experiments to natural diamonds.

The diamond parcels (Table 1 ) were studied under an optical microscope to remove all fibrous, milky, cubic or fragmental stones. The rest of the diamonds were divided according to the general morphology (Table 1) and investigated in reflected light under an optical microscope and using Field Emission Scanning Electron Microscope (FE SEM) Hitachi S-4700 FEG at Dalhousie University. Misery parcel containing several hundreds of stones, was picked for all octahedron diamonds and for the representative examples of hexoctahedrons. We divided octahedron stones into three groups: 1a diamonds with numerous trigon etch pits, 1b diamonds with various degree of volume resorption (morphological changes) and surface resorption (etching), 1c - octahedrons with trigon etch pits completely covering [111] face. The hexoctahedron stones were divided into $2 \mathrm{a}$ - not frosted and $2 \mathrm{~b}$ frosted diamonds (Table 1). 


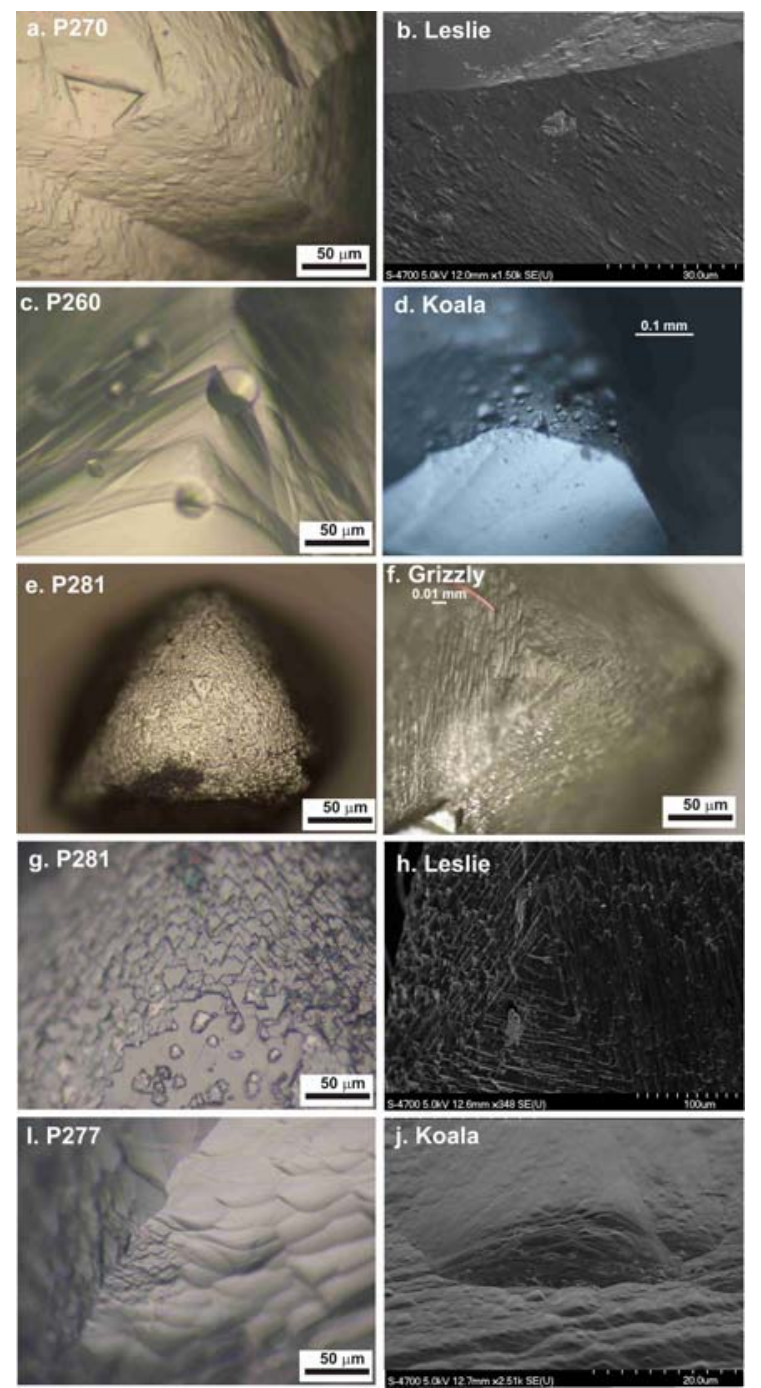

Fig. 1. Photographs and secondary electron images of similar diamond features produced experimentally at $1350^{\circ} \mathrm{C}, 1 \mathrm{GPa}$ in $\mathrm{H}_{2} \mathrm{O}$-rich and $\mathrm{CO}_{2}$-rich fluids (left column) and observed on natural diamonds (right column).

Table 1. Diamond parcels (see text for the description of the diamond groups).

\begin{tabular}{lllll}
\hline Kimberlite & \multicolumn{2}{l}{ Grizzly Misery } & Koala & Leslie \\
Parcel & \multicolumn{2}{l}{ GR-124 M-95 } & K-95 & LS-95 \\
Weight (carats) & 15.3 & 25 & 4.613 & 4.623 \\
\hline 1.Octahedrons & & & & \\
$1 a$ & 4 & 1 & 4 & 16 \\
$1 b$ & 23 & 7 & 16 & 30 \\
$1 c$ & 3 & 1 & 2 & 4 \\
2. Hexoctahedrons & & & \\
$2 a$ & 18 & 21 & 85 & 54 \\
$2 b$ & 51 & 10 & 51 & 26 \\
\hline
\end{tabular}

Octahedrons: In Misery kimberlite trigon etch pits are relatively rare even on significantly rounded (resorbed) diamonds. The most typical octahedrons are rounded with striation along the sides and very few shallow flatbottomed trigons. This indicates oxidation in extremely fluid-rich conditions and high proportion of $\mathrm{H}_{2} \mathrm{O}$.
In Koala diamonds trigons are more common and not as shallow. Presence of small hillocks and rounded steps on resorbed surfaces suggests oxidation in magma equilibrated with a fluid phase rich in $\mathrm{H}_{2} \mathrm{O}$. In Leslie, on contrary, even slightly rounded (resorbed) diamonds have abundant trigons with their walls formed by micro step-faces indicating low fluid content. The resorbed surfaces have very sharp features very similar to the ones produced in experiments with fluid loss. In Grizzly all the trigons are formed by micro step-faces. All features on these diamonds have very sharp corners indicating very low content of fluid or, possibly, its absence. Some diamonds resemble experimentally-etched diamonds with surface graphitization (Fig.1e-h).

Hexoctahedrons: Misery kimberlite has many glossy hexoctahedrons with very smooth surfaces, some of which have individual "drop-like" hillocks. Such surfaces can be produced over a large range of $\mathrm{H}_{2} \mathrm{O}$ $\mathrm{CO}_{2}$ ratios in the reacting fluid. Striation indicates presence of $\mathrm{H}_{2} \mathrm{O}$-rich fluid. The roundness of the features suggests oxidation in extremely fluid-rich system. Koala kimberlite has many similar smoothsurface stones with "drop-like" hillocks. However, hexoctahedrons with more "busy" surfaces completely covered with hillocks are also very common. Some diamonds have rounded triangular hillocks (Fig.1j) typical for the oxidation in $\mathrm{CO}_{2}$-rich fluid. This is the only parcel with widely-developed "disks" common for oxidation in $\mathrm{H}_{2} \mathrm{O}$-rich fluids (Fig.1d). Abundant deformation lamellae control development of small hillocks. The smooth-surface glossy hexoctahedrons are almost absent from Leslie and Grizzly populations. Most of the Grizzly diamonds are frosted. They are covered by micro step-faces with sharp corners sticking out (Fig.1f,h), which were observed only in experiments where extensive fluid loss caused development of surface graphitization. Some of the Leslie hexoctahedrons have rounded well-developed hillocks, but at the same time develop areas with sharp features common for fluid-loss conditions (Fig. 1b) and micro step-faces similar to the Grizzly diamonds.

\section{Water in phenocrystal olivine}

Concentration and occurrence of hydroxyl in olvines from kimberlites was measured using FTIR spectroscopy (for methods and classification of OH IR absorption bands see Matveev and Stachel, 2007). To date 15 to 20 grains were analyzed per kimberlite (Fig.2). Additional data for olivines from Grizzly and Misery kimberlites are available from Matveev and Stachel (2007). All kimberlites showed wide variety of $\mathrm{OH}$ concentrations and spectral types. However, unlike olivines from other kimberlites olivines from Grizzly and Leslie did not show Group 2 OH IR absorption bands. Olivines from Panda and Beartooth kimberlites contained the highest concentrations of water approaching 600 ppm. Olivines from Misery and Koala kimberlites contained medium concentrations of water (up to 450 ppm) and Group 2 bands are associated with 
various Group 1 bands implying wide range of pressures.

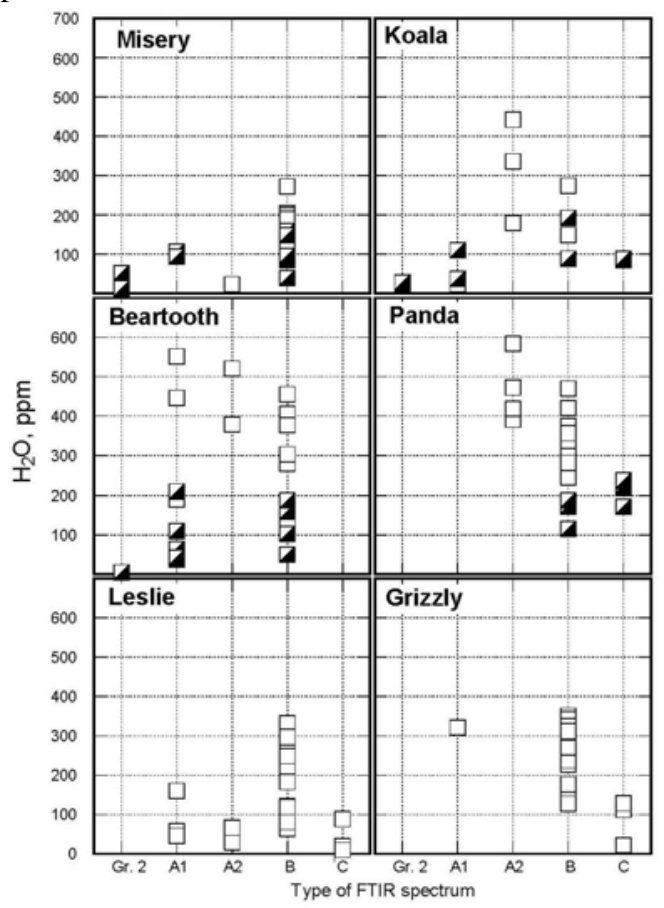

Fig. 2. FTIR spectra of olivines: Gr 2 - spectra with Group 2 bands only where type of Group 1 bands is undefined; A1 - high pressure Group 1 bands (P > 2.5 $\mathrm{GPa})$; A2 - medium pressure Gr.1 (1.5 - $2 \mathrm{GPa})$; B moderate pressure Gr. 1 (>1.5 GPa); $\mathrm{C}$ - low pressure Gr. 1 (< $1 \mathrm{GPa}$ ). Open symbols represent spectra with Group 1 bands only. Half filled symbols represent spectra with both Group 1 and Group 2 bands.

\section{Discussion}

The most significant difference between surface features of the four studied diamond populations is the presence of sharp dissolution forms in Leslie and Grizzly diamonds indicating loss of the fluid by these two kimberlites. Absence of the Group 2 bands in phenocrystal olivines from these kimberlites support this conclusion (Fig.2). We propose that loss of the fluid possibly at Moho slowed down the ascent of these two kimberlites causing the larger degree of diamond resorption and decrease of the diamond grade. Development of complex etching and sharp irregular resorption forms in these "dry" conditions significantly affected diamond quality. Absence or low content of the fluid may have resulted in a less explosive eruption of these two kimberlite magmas and formation of kimberlite pipes completely filled with magmatic facies. Loss of magmatic fluid agrees with an increase in oxygen fugacity $\left(\mathrm{fO}_{2}\right)$ recorded by the groundmass perovskite in the Grizzly kimberlite (Canil and Bellis, 2007). Our data suggests that the main reason for the geology of Leslie and Grizzly kimberlites being so different from the surrounding pipes of the same age is the loss of the fluid. It is possible that absence of the Group 2 bands in FTIR spectra of kimberlitic olivine can be used as an indication of early fluid loss, poor diamond quality and low diamond grade resulted from the slow emplacement.

The Misery, Koala, Panda and Beartooth kimberlites have diamonds with features developed in the presence of a free fluid phase. Phenocrystal olivine from all these kimberlites have Group 2 bands (Fig.2) supporting presence of the fluid. However, Misery and Koala diamonds have much higher proportion of the rounded forms that may be a result of a more profound resorption accompanied by significant weight loss or might be caused by oxidation in a fluid extremely rich in $\mathrm{H}_{2} \mathrm{O}$ where diamonds become rounded even at very low weight losses (see Fedortchouk et al., 2007). On the other hand, Misery has much higher diamond grade (4 cts/tonne) than Panda and Beartooth (around $1 \mathrm{cts} / \mathrm{t}$ ). FTIR spectra of olivines shows presence of fluid in the two later kimberlites at greater depths (> 2GPa), and the $\mathrm{CO}_{2}$-rich composition of this fluid. This would cause a longer exposure of the diamonds to the oxidation reaction with the early formed fluid. At the same time, the high $\mathrm{CO}_{2}$-content of the fluid favored good preservation of the octahedron morphology even at high weight losses. Misery magma, on contrary, was undersaturated in volatiles until shallower depth. This helped preservation of diamond initial weight and high grade of the kimberlite. Release of large amount of $\mathrm{H}_{2} \mathrm{O}$-rich fluid at shallow depth caused significant rounding of the diamonds with minimal weight loss and extremely fast emplacement of this kimberlite. Difference in the depth of the fluid exolution in the Panda-Beartooth and the Misery magmas may have resulted in $\mathrm{C}-\mathrm{O}-\mathrm{H}$ fluid equilibria buffering the redox state of the former two kimberlites and ferric-ferrous equilibria - of the later one. This would explain more reduced final $\mathrm{fO}_{2}$ values reported by Canil and Bellis (2007) for Panda (NNO-2) and more oxidized final $\mathrm{fO}_{2}$ reported for Misery (NNO+6).

\section{References}

Canil, D., Bellis, A.J. 2007. Ferric iron in CaTiO3 perovskite as an oxygen barometer for kimberlite magmas II: applications. Journal of Petrology 48 (2), 231 - 252.

Fedortchouk, Y., Canil, D., Semenets, E., 2007. Mechanisms of diamond oxidation and their bearing on the fluid composition in kimberlite magmas. American Mineralogist 92, $1200-1212$.

Fedortchouk, Y., Canil, D., Carlson, J.A. 2005. Dissolution forms in Lac de Gras diamonds and their relationship to the temperature and redox state of kimberlite magma. Contributions in Mineralogy and Petrology 150, 54-69.

Gurney, J.J., Hildebrand, P.R., Carlson, J.A., Fedortchouk, Y., Dyck, D.R. 2004. The morphological characteristics of diamonds from the Ekati property, Northwest Territories, Canada. Lithos 77, 21-38.

Matveev, S., Stachel, T., 2007. FTIR spectroscopy of OH in olivine: a new tool in kimberlite exploration. Geochimica et Cosmochimica Acta 71 (22), 55285543.

Papale, P., Polacci, M. 1999. Role of carbon dioxide in the dynamics of magma ascent in explosive eruptions. Bulletin of Volcanology 60, 583-594.

Skinner, E.M.W., Marsh, J.S., 2004. Distinct kimberlite pipe classes with contrasting eruption processes. Lithos 76 (1-4), 183-200. 